EPiC Series in Built Environment
Volume 1, 2020, Pages 152-160
$\begin{gathered}\text { Associated Schools of Construction Proceed- } \\ \text { ings of the 56th Annual International Conference }\end{gathered}$

\title{
Multi-disciplinary Teams - the Continuing Challenge to Collaborate in the Classroom
}

\author{
James P. Smith, Ph. D., Evan Bingham, Ph. D., and Clifton Farnsworth, Ph. D. \\ Brigham Young University \\ Provo, Utah
}

The need to collaborate in the Owner/Architecture/Engineering/Construction (OAEC) industry continues to grow. As owners increasingly choose alternative delivery methods for their projects, the ability of key participants to effectively work with one another is becoming a critical and defining skill. In their 2016 accreditation update, the American Council for Construction Education (ACCE) decided to include a new Student Learning Outcome (SLO) specific to this growing need. ACCE SLO \#9 states that students graduating from accredited institutions are expected to show the ability to "apply construction management skills as a member of a multi-disciplinary team." This requirement poses a significant challenge to many universities. This paper provides qualitative data from multi-disciplinary courses conducted at 3 universities. Participating administration, faculty and students provided data that supports anticipated benefits of multi-disciplinary courses and enhances previous findings. Observed challenges in addition to those provided by extant literature were identified. Observations and interviews highlight the importance of differentiating between multi-disciplinary interactions and inter-disciplinary interactions. It is recommended that interested programs carefully consider program and course design as it relates to these differences and additionally identified issues as the challenge to collaborate continues.

Key Words: Multi-disciplinary, Collaboration, Accreditation, Student Learning Outcomes

\section{Introduction}

In recent years it has been well established that collaboration between the parties to the construction process is critical. Evolving and alternative project delivery methods, technological advancements in Building Information Modeling (BIM) and other software platforms, and increasing building complexity have heightened the industry's awareness of and focus on this skill (Becerik-Gerber et al., 2012; Cheng et al., 2001; Cheung et al., 2013). Widespread high-speed internet availability, efficient communication tools, and cloud-based document management systems have given globally diverse teams the opportunity to interact and collaborate at different levels than previously experienced.

The importance for the rising generation of Architecture/Engineering/Construction (AEC) participants to be able to collaborate effectively is also highlighted in recent accreditation requirements. The 
Multi-disciplinary Teams - the Continuing Challenge to Collaborate in the Classroom J. Smith et al.

American Council for Construction Education (ACCE), one of the primary accrediting agencies for US construction management programs, recently updated their learning outcomes to include a requirement for accredited programs to show the students' ability to "apply construction management skills as a member of a multi-disciplinary team" - Student Learning Outcome (SLO) \#9 (ACCE, 2016) . Similarly, in their 2017 revision, the Accreditation Board for Engineering and Technology (ABET) included criterion 3(d), "Engineering programs must demonstrate that their graduates have an ability to function on multi-disciplinary teams," (ABET, 2017). Sulbaran (2003) provided an example of a successful accreditation based on a course combining architecture, construction management, and software engineering students. The reality for most universities is, however, this requirement continues to pose a significant challenge.

This particular project was undertaken in preparation for the development of an Integrated Project Delivery certificate program. The researchers selected three university programs that were successfully conducting multi-disciplinary courses for observation and analysis. The following questions were addressed through this research effort:

1. What key practices, program elements, and/or course elements have enabled successful and sustainable multi-disciplinary courses?

2. Do the anticipated benefits of multi-disciplinary engagement continue?

3. After a few years of implementation, what new challenges are faculty and students experiencing with multi-disciplinary courses?

Upon completion of these case studies, it was evident that many approaches existed, some of which create the basis of the current literature. Some of those early efforts described in the literature have now been discontinued, and others have survived and continued to evolve. In those cases, new challenges have surfaced that were not previously identified in the literature. It is the authors' opinion that the continuing analysis of multi-disciplinary efforts in academia is an important part of establishing a beneficial multi-disciplinary experience as a standard part of the AEC students' educational experience, as opposed to an exception.

\section{Literature Review}

Despite the reality that in most industries multi-disciplinary engagement is a necessity to solve realworld problems, academia has a long history of remaining intensely disciplinary and arguably even possessively segregated. However, researchers have studied the benefits and challenges of multidisciplinary courses in many different industries for some time now (see Hazard, 1972; Newell \& Green, 1982; and Newell, 1992).

In more recent years, multiple research efforts specific to the multi-disciplinary efforts in the AEC industry have also been conducted. Although all universities do not have access to the wide range of possible collaborative partners, (e.g., architecture, civil engineering, interior design, construction management, etc.), most have access to at least one. Debs \& Brissi (2019) conducted a study to analyze common multi-disciplinary combinations according to course enrollment. Their study showed that courses from architecture and civil engineering programs are more likely to attract construction students and vice versa than those from interior design programs. Other possibilities include engagement through research projects (Reyes et al. 2013), capstone projects combining students from Civil, Environmental, Electrical and Mechanical Engineering together to develop design solutions to real world industry-provided problems (Turner \& Reynolds, 2014), and team competitions (Reyes et al., 2013). 
Multi-disciplinary Teams - the Continuing Challenge to Collaborate in the Classroom J. Smith et al.

The majority of documented efforts within the AEC disciplines are based on the design, implementation and analysis of a single specific course attempting to engage construction management students with architecture, civil engineering, and/or interior design students. Wendler and Segner (1989) were early pioneers in this area testing co-requisite classes and linked sections which encouraged structured interaction between professors and students (preferred approach).

O'Brien et al. (2003) published a description of an internet-based multi-disciplinary capstone course focusing on collaborative design. This is important because it provides a model for universities that don't have "in-house" sister programs with whom to collaborate. At the time of O'Brien's study, it was determined that available software did not allow for true collaboration amongst the parties, however the experience was still deemed beneficial.

Callahan and Ryan published various papers related to the development of a multi-disciplinary course and came to the following consolidated and paraphrased conclusions:

1. Challenges related to different motivations for learning (e.g., construction content delivered with the intent to increase efficiency and profit versus creative interests of design students).

2. Awareness of the introduction of positive and negative bias via internships.

3. Suggestion that more construction administration emphasis in design curriculums and more design process emphasis in construction curriculums could affect improved collaboration.

4. Disciplinary friction is an important experience for students and embracing it in the multidisciplinary course environment could be valuable (Callahan \& Ryan, 2009).

5. Success of the effort depended greatly on the attitude, motivation and commitment of the participating faculty (Ryan \& Callahan, 2007).

Holley \& Dagg (2005) recognized key benefits to architecture and construction management students participating in a newly designed multi-disciplinary course as follows: 1) students recognized the contribution of the other discipline to the overall success of the project, and 2) reduced disconnect between the disciplines and increased mutual respect and empathy across the disciplines.

Each of these course examples adopt a pedagogical approach to define the collaborative interactions between the disciplines. The differences between these approaches is somewhat nuanced, but it is an important distinction and has been compared in literature both within and without the AEC academic realm.

\section{Multi-disciplinary vs Inter-disciplinary vs Trans-disciplinary Course Design}

One key element that must be included in this discussion is related to terminology and course design intent. As previously mentioned, ACCE SLO \#9 and ABET criterion 3(d) specify that students should demonstrate an ability to apply construction management skills, or at least function, as a member of a multi-disciplinary team. However, researchers in psychology point out that there are important differences in the commonly-used semantics (Collin, 2009). The term multi-disciplinary suggests individuals from different disciplines working in parallel, or sequentially. This would be similar to a Serial or Concurrent collaboration as indicated in Figure 1 (Elvin, 1998). Inter-disciplinary, on the other hand, suggests an iterative reliance on the expertise of the other disciplines, as seen in the Integrative model of Figure 1. The third possibility would be a trans-disciplinary course design. While not represented in Elvin's (1998) model, a transdisciplinary approach would suggest that participants operate in concert above and beyond their individual disciplines. 
Multi-disciplinary Teams - the Continuing Challenge to Collaborate in the Classroom J. Smith et al.

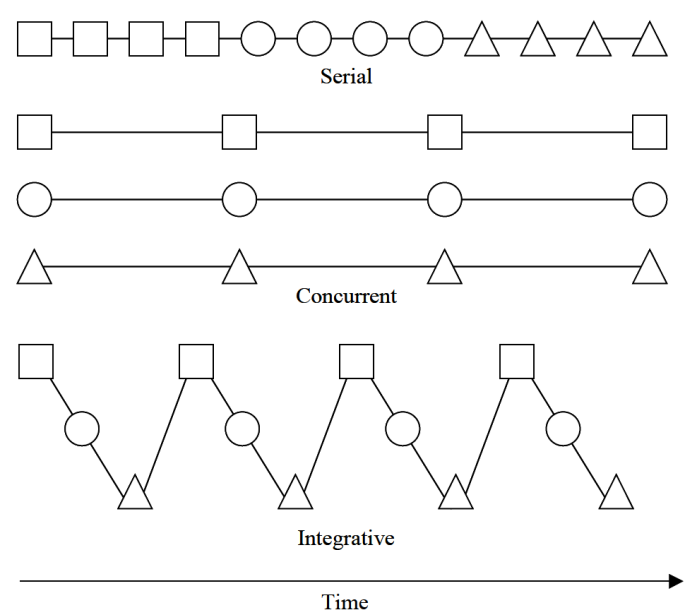

Figure 1. Approaches to collaboration (Elvin, 1998)

According to these definitions, the majority of multi-disciplinary efforts found in the literature are actually inter-disciplinary efforts. The current AEC industry and most alternative project delivery methods are more accurately inter-disciplinary by design. For the remainder of this paper the term inter-disciplinary will represent the multi-disciplinary and inter-disciplinary efforts being discussed.

\section{Methodology}

The methodology selected for this project was three case studies of programs that were successfully conducting inter-disciplinary courses. For consistency and comparison, only programs that combine the Architecture (Arch) and Construction Management (CM) disciplines were selected. Groat \& Wang (2013) claimed that case study research is useful in the development of theory and allows the researcher to analyze complex and over-lapping variables. The authors determined that the need for continuing theoretical development and the inherent multivariate nature of inter-disciplinary efforts justified the selected methodology. Unlike the majority of previous literature in this area, this project was conducted by a third party researcher, not an individual that was directly or indirectly engaged in the creation and implementation of the various courses and programs under consideration.

The three university case studies were selected based on a track record of successful implementation of inter-disciplinary courses as identified through individual conversations and phone interviews. Onsite visits allowed for an in-depth data gathering effort relative to these programs to determine what practices appeared to be sustaining the effort, and what new issues warranted consideration.

Qualitative data was gathered from these three case studies in the form of observations, interviews and analysis of relevant written documentation (e.g., course syllabi, curriculum, etc.) The rich data from these various interactions was then analyzed and synthesized for inclusion in this paper.

\section{Findings and Discussion}

Each of the studied programs took differing approaches in their efforts to provide an inter-disciplinary experience for their students. To set the stage for each case study, a few selected details in this regard are included in Table 1. 
Multi-disciplinary Teams - the Continuing Challenge to Collaborate in the Classroom J. Smith et al.

Table 1

Case study details

\begin{tabular}{llll}
\hline & University X & University Y & University Z \\
\hline Program type* & Undergraduate & Undergraduate & Graduate \\
CM accreditation & ACCE & None & ACCE \\
$\begin{array}{l}\text { Arch accreditation } \\
\text { Course model }\end{array}$ & NAAB & NAAB & NAAB \\
& $\begin{array}{l}\text { (1) Lecture } \\
\text { (2) } 2 \text { separate but } \\
\text { concurrent capstone } \\
\text { courses }\end{array}$ & Studio/Capstone & Studio \\
Faculty assignment & $\begin{array}{l}\text { (1) CM } \\
\text { (2) Designated Arch } \\
\text { and CM faculty }\end{array}$ & Arch and CM & Arch and CM \\
& & \\
\hline * This designation is specific to the program where the inter-disciplinary course under review was being held, not to what is \\
offered at the university. Each of the studied programs offer undergraduate and graduate level degrees.
\end{tabular}

Members of each university's administration, faculty and students were asked to answer and discuss the three guiding research questions. Their individual, collected and aggregated responses along with support gained via observations follow. To allow for emphasis on common themes the data is organized by topic rather than by university.

\section{Key Practices}

\section{Program Elements}

Faculty. A common theme for sustaining inter-disciplinary efforts within programs among the three case studies was the importance of faculty champions - also highlighted in the literature (Ryan \& Callahan, 2007). In a deeper review, two other key elements were discovered. First, administrative and faculty respondents felt that a defining characteristic of successful and sustained courses was administrative support. However, it also became clear that administrative support, even administrative mandates, were insufficient to create the desired outcome. This was true regardless of the program type or adopted course model. One program chair specifically mentioned that despite strong and proactive administrative support, there was likely only one member of their faculty that could make it work. Another program chair highlighted this as the single biggest challenge they faced in achieving their targeted outcome. When those apparently unique faculty members that are capable of managing an inter-disciplinary course change positions or move programs, the courses they lead often fall apart. At University Z, the faculty champions from Arch and CM made the decision to move their efforts from the undergraduate to the graduate level and very quickly the undergraduate effort fell apart. Second, finding the right faculty to teach the courses was only part of the challenge. In addition to previously identified challenges of established departmental boundaries and assignment of faculty credit (Macdonald, 2012; Mills \& MacDonald, 2013), the faculty themselves often struggled to collaborate and communicate, ironically. Part of this was due to the widely agreed upon idea that teaching an inter-disciplinary course places a much higher demand on faculty involvement and time than a traditional course. One faculty member suggested that running an inter-disciplinary studio consumed approximately 2-3 times the workload per contact hour. This reportedly impacted their ability to accomplish other important faculty responsibilities such as scholarship, and frankly discouraged long term involvement in the class. 
Multi-disciplinary Teams - the Continuing Challenge to Collaborate in the Classroom J. Smith et al.

Accreditation. While accrediting bodies are encouraging inter-disciplinary experiences, accreditation requirements can also be a limiting factor. Whether perceived or real, some programs and faculty struggle to make space in their curriculums for inter-disciplinary interactions under the auspices of accreditation requirements. In this sense, University $\mathrm{Y}$ benefited from not needing to meet accrediting requirements, allowing them to design and conduct a unique inter-disciplinary course. Utilizing multiple semesters for connected studio classes, Arch and CM students were able to experience and navigate real world problems and provide deliverables to actual owners. According to involved professors, this unique approach had actually prevented their accreditation pursuit. The course experience appeared to be very valuable to those students from University Y that participated, but in consultation with the accredited program leadership, the infrastructure and flexibility necessary to be successful in conducting this kind of course were not current characteristics of their programs.

\section{Course Elements}

Value systems. An interesting challenge identified in previous literature is that students from the various programs generally have different motivations to learn (Callahan \& Ryan, 2007). In an attempt to understand this better, researchers pursued discussions with respondents relating to value systems and lifestyles of involved disciplines. Table 2 includes common issues and preferences of Arch and CM students identified during the case studies that must be navigated during design of an inter-disciplinary course. Some of these preferences are established by patterns and trends students experience in their individual programs, and some appear to be more deeply related to the stereotypes of individuals that pursue careers in Arch versus CM. The inclusion of students from additional disciplines (e.g., civil engineering, interior design, mechanical engineering, etc.) would likely compound the challenge to oversee courses of this nature. None of these preferences are meant to be portrayed as right or wrong, only different.

Table 2

Course Design Considerations - Comparison of Arch and CM Student Preferences

\begin{tabular}{|c|c|c|}
\hline Issue & Arch Student & CM Student \\
\hline Class scheduling & Friday class, late nights & $\begin{array}{l}\text { Fridays are for working in } \\
\text { industry (or hunting) }\end{array}$ \\
\hline Assignment type & $\begin{array}{l}\text { Iterative assignments are } \\
\text { common and beneficial }\end{array}$ & $\begin{array}{l}\text { Duplication is viewed as } \\
\text { busy work }\end{array}$ \\
\hline Course design & Studio culture & Lecture/Lab culture \\
\hline Terminology & $\begin{array}{l}\text { Industry-specific language and } \\
\text { acronyms }\end{array}$ & $\begin{array}{l}\text { Different industry-specific } \\
\text { language and acronyms }\end{array}$ \\
\hline Location & $\begin{array}{l}\text { More comfortable with Arch } \\
\text { spaces }\end{array}$ & $\begin{array}{l}\text { More comfortable with CM } \\
\text { spaces }\end{array}$ \\
\hline
\end{tabular}

Deliverables and grading. In courses that were designed as truly inter-disciplinary, as defined previously, respondents from each level generally shared similar frustrations. Key identified issues are as follows: 
Multi-disciplinary Teams - the Continuing Challenge to Collaborate in the Classroom J. Smith et al.

- Quality of the received deliverable - Since both disciplines are basing their various phases of work on what is provided by their partners, the overall quality of their deliverables at each stage is at least partially dependent on the quality of what was given to them. In an iterative/integrated collaboration process (see Figure 1), poor quality tends to be magnified over time. While this is very true to industry realities, it challenges established educational and grading practices from the faculty side, and expectations and perceived fairness on the student side. Some CM students commented that this was no problem for them because, "their architects are really good", but the opposite experience was also common.

- Sequencing of deliverables - Programs and administering faculty recognized the challenge of sequencing deliverables between the students. What should CM students be doing while they wait for design updates from their Arch counterparts? What should Arch students be doing while they wait for estimates or constructability analyses from their CM counterparts? Most participating faculty filled this gap using discipline-specific assignments outside of the interdisciplinary or shared project. Universities $\mathrm{Y}$ and $\mathrm{Z}$ experimented with varying levels of cross-training during the gaps as well, however feedback was mixed. As it relates to the final deliverable, the need to wait on a counterpart also introduced challenges accomplishing even basic deliverables within a single semester. University $\mathrm{Y}$ had the flexibility to extend their studio over multiple semesters so they could accomplish more appreciable deliverables, but other universities described struggling in this regard. University X attempted to circumvent this problem by having Arch student do preliminary drawings during the semester before in a regular studio course.

- Discipline specific knowledge levels - Many administrators believed that early and regular interaction between the disciplines was a key element to creating successful interdisciplinary experiences for the students. Unfortunately, the ability for students to integrate is generally limited as underclassmen due to their limited knowledge and experience in their own discipline. Faculty were spending excessive amounts of time managing the minutia of their students (e.g., keeping track of screws for the project). This issue impacts also the quality of the deliverable, as discussed previously. This challenge was part of what encouraged University $Z$ to begin the inter-disciplinary efforts at the graduate level.

- Grading (generally) - Most faculty and students shared common concerns related to grading. When multiple professors are involved, who is responsible for grading? What portion of the grade is actually representative of the individual's effort? Are teams selected at random, by the professor, or by the students themselves? What happens if you draw the proverbial short stick with regards to your team members?

\section{Benefits}

Despite the various discussed challenges and complaints regarding grading and required time among others, participants at every level believed the inter-disciplinary effort to be valuable and beneficial. Even begrudgingly in some cases, interviewed students would admit a recognition of value from the experience. Responses from the discussions about benefits are in line with previous literature on the subject. Relevant sample responses are as follows:

- Student - Students experience a masterbuilder mindset by considering all project aspects.

- Student - I wish I could have experienced this earlier in my academic career.

- Student - Gives me a sense of the real world, I get to see the other side.

- Student - I have a better understanding of my role and the roles of the other players, but even more importantly an understanding of the different personality types. 
Multi-disciplinary Teams - the Continuing Challenge to Collaborate in the Classroom J. Smith et al.

- Faculty - Students are exposed to a holistic perspective as early as possible, helping them avoid the silo mindset from the beginning.

- Faculty - This is the real experience they will have when they graduate.

- Administrator - It is an exceptional experience and it is worth the risk.

- Administrator - Industry loves it, students become more understanding of a holistic view.

\section{Conclusions}

Inter-disciplinary experiences for students are an important part of modern Arch and CM programs. Success of these efforts is heavily dependent on the participating faculty members and on the level of attention given to program structure and course design. Programs are encouraged to carefully consider differing student backgrounds, established program patterns, and the distinction between multidisciplinary, interdisciplinary, and trans-disciplinary course design. The authors recommend continued development, analysis and documentation of inter-disciplinary course efforts to enhance the theory surrounding these courses and give various examples to those attempting it for the first time.

\section{References}

Accreditation Board for Engineering and Technology (ABET). (2017). Accreditation Policy and Procedure Manual (APPM), 2017-2018. Retrieved from

http://www.abet.org/accreditation/accreditation-criteria/accreditationpolicy-and-proceduremanual-appm-2017-2018/

American Council for Construction Education (ACCE). (2016). Standards and criteria for accreditation of postsecondary construction education degree programs. Retrieved from https://www.acce-hq.org/images/uploads/Doc_103_Updated_0915171.pdf

Becerik-Gerber, B., Ku, K., \& Jazizadeh, F. (2012). BIM-Enabled Virtual and Collaborative Construction Engineering and Management. Journal of Professional Issues in Engineering Education and Practice, 138(3), 234-245. doi:10.1061/(asce)ei.1943-5541.0000098

Callahan, M.P., \& Ryan, R.C. (2009). Pedagogy Transcends Tradition: Practice and Pitfalls. The International Journal of Interdisciplinary Social Sciences, Volume 4, 2009.

Cheng, E. W., Li, H., Love, P. E., \& Irani, Z. (2001). Network communication in the construction industry. Corporate Communications: An International Journal, 6(2), 61-70.

Cheung, S. O., Yiu, T. W., \& Lam, M. C. (2013). Interweaving Trust and Communication with Project Performance. Journal of Construction Engineering and Management, 139(10), 941-950.

Collin, A. (2009). Multidisciplinary, interdisciplinary, and transdisciplinary collaboration: implications for vocational psychology. Int J Educ Vocat Guidance, 9:101-110.

Debs, L., \& Brissi, S.G. (2019). Undergraduate Construction Students' Likelihood of Attending Courses in Other AEC Disciplines. 55 th ASC Annual International Conference Proc, 89-97. 
Multi-disciplinary Teams - the Continuing Challenge to Collaborate in the Classroom J. Smith et al.

Elvin, G. (1998). A process model for integrated design and construction. Unpublished doctoral dissertation, Department of Architecture, University of California at Berkeley.

Groat, L. N., \& Wang, D. (2013). Architectural research methods. John Wiley \& Sons.

Hazard Jr, G. C. (1972). Interdisciplinary Courses and Programs in Law and Special Work: A Survey. Family Law Quarterly, 6, 423.

Holley, P.W., \& Dagg, C. (2005). Multidisciplinary Collaborative Experiences: A Case Study in Sustainable Construction and Design. ASC Proceedings of the $41^{\text {st }}$ Annual Conference, University of Cincinnati, Cincinnati, OH, April 6-9, 2005.

Macdonald, J.A. (2012). A framework for collaborative BIM education across the AEC disciplines. AUBEA 2012: Annual Conference of Australasian Universities Building Educators Association, Sydney, Australia, July 4-6, 2012.

MacDonald, J., \& Mills, J. (2013). An IPD approach to construction education. Construction Economics and Building, 13(2), 93-103. doi:http://dx.doi.org/10.5130/AJCEB.v13i2.3324

Maclaren, A. J., Wilson, M., Simmonds, R., Hamilton-Pryde, A., Mccarthy, J., \& Milligan, A. (2017). Educating Students for the Collaborative Workplace: Facilitating Interdisciplinary Learning in Construction Courses. International Journal of Construction Ed. and Research, 13(3), 180-202.

Newell, W. H., \& Green, W. J. (1982). Defining and teaching interdisciplinary studies. Improving college and university teaching, 30(1), 23-30. DOI:10.1080/00193089.1982.10533747

Newell, W. H. (1992). Academic disciplines and undergraduate interdisciplinary education: Lessons from the School of Interdisciplinary Studies at Miami University, Ohio. European Journal of Education, 27(3), 211-221.

O’Brien, W., Soibelman, L., \& Elvin, G. (2003). Collaborative design processes: an active-and reflective-learning course in multidisciplinary collaboration. Journal of Const Ed, 8(2), 78-93.

Reyes, M.D., Holliday, L.M., \& Butko, D.J. (2013). Involving Construction Students in Research through Collaboration and a National Sustainability Competition. $49^{\text {th }}$ ASC Annual International Conference Proceedings, Cal Poly, San Luis Obispo, CA.

Ryan, R.C., \& Callahan, M.P. (2007). Developing and Teaching a Collaborative Design and Construction Administration Course. 43 ${ }^{\text {rd }}$ ASC Annual International Conference Proceedings, Northern Arizona University, Flagstaff, AZ.

Sulbaran, T. (2003). An Experience of a Multidisciplinary Project Involving Architecture Design Quantity Takeoff and Virtual Reality Framed within TAC-ABET Accreditation Criteria. $39^{\text {th }} A S C$ Annual International Conference Proceedings, Clemson University, Clemson, SC.

Turner, C.J., Reynolds, S.M. (2014). Multidisciplinary Construction Engineering Design Projects. $121^{\text {st }}$ ASEE Annual Conference and Exposition, Indianapolis, IN, June 15-18, 2014.

Wendler, W.V., \& Segner, R.O. (1989). Integrating Design and the Construction Science Class. ASC Proc of the $25^{\text {th }}$ Annual Conference, University of Nebraska-Lincoln, April 1989, 135-140. 